\title{
Long-term outcomes of Fine Needle Diathermy for established corneal neovascularisation
}

\author{
S Trikha, ${ }^{1}$ S Parikh, ${ }^{2}$ C Osmond, ${ }^{3}$ D F Anderson, ${ }^{1}$ P N Hossain ${ }^{1,2}$
}

- Additional material is published online only. To view please visit the journal online (http://dx.doi.org/10.1136/ bjophthalmol-2013-303729).

${ }^{1}$ Department of Ophthalmology, University Hospital Southampton, Southampton, UK

${ }^{2}$ University of Southampton School of Medicine, University Hospital Southampton, Southampton, UK

${ }^{3}$ MRC Epidemiology Research Unit, University Hospital Southampton, Southampton, UK

Correspondence to Mr P N Hossain, Department of Ophthalmology, University Hospital Southampton,

Tremona Road, Southampton S016 6YD, UK:

P.N.Hossain@soton.ac.uk

Received 2 June 2013 Revised 8 October 2013 Accepted 11 December 2013

To cite: Trikha S, Parikh S, Osmond $\mathrm{C}$, et al. Br J Ophthalmol Published Online First: [please include Day Month Year] doi:10.1136/bjophthalmol2013-303729

\section{ABSTRACT}

Background/aims Corneal neovascularisation (CoNV) can lead to significant ocular comorbidity with reduction in vision and cosmesis. A number of techniques have been described to reduce CoNV, but these can be expensive. Our study aimed to determine the safety, efficacy and long-term outcomes of fine needle diathermy (FND) for CoNV.

Methods A 5-year retrospective study identified all cases of FND. Indications, intraoperative complications, and postoperative visual acuity, after treatment and retreatments, were documented, along with the procedure time. Evidence of regression and number of retreatments were identified.

Results 56 eyes from 52 patients underwent FND for CoNV. The main indications included herpes simplex keratitis (HSK) $(53 \%, n=25)$ and microbial keratitis/ peripheral ulcerative keratitis $(13 \%, n=6)$. Pretreatment acuity was significantly correlated with extent of CoNV $(p=0.044)$. One complication was noted during the procedure-an intrastromal and subconjunctival haemorrhage (rate $2 \%$ ). $68.1 \%$ of patients demonstrated regression at first follow-up (mean 6.9 weeks), and $89.3 \%(n=42)$ showed regression with two or less treatments. Mean post-FND acuity was 0.72 (range $-0.2-3.0)$ vs $0.82(-0.2-3.0)$ preprocedure $(p=0.08)$. VA improved in the HSK subgroup $(p=0.012)$. Mean follow-up was 18.9 months (range 1-56 months). Conclusions In the largest case series reported, FND appears to be a safe and effective technique in the long term to induce regression of CoNV, with significant improvement in the VA of patients with HSK.

\section{INTRODUCTION}

Corneal neovascularisation (CoNV) is a common condition, often resulting in marked ocular morbidity and a subsequent detrimental effect upon vision. Lee $e t a l^{1}$ found CoNV in 35 of 845 consecutive cases attending the eye clinic, with $12 \%$ associated with reduced visual acuity. The process of CoNV has been well described and is often an innate and physiological response essential for corneal repair and regeneration. ${ }^{2}$ Ocular surface disease processes result in breakdown of corneal privilege, loss of corneal clarity, scarring, and subsequent deposition of lipid and calcium. ${ }^{2}$ The follow-on effects from this are often marked discomfort and a profound reduction in vision and cosmesis. ${ }^{3}$ Furthermore, the presence of CoNV increases the risk of subsequent corneal graft failure, as described by a recent meta analysis published by Bachmann et al, ${ }^{4}$ illustrating a directly proportional relationship between graft failure and the number of quadrants of CoNV preoperatively. ${ }^{5}$ Despite advances in the understanding of CoNV and the emergence of topical anti-vascular endothelial growth factor (VEGF) agents, ${ }^{6}$ definitive treatment strategies are lacking, often due often to a lack of effectiveness and safety, and as yet fall short of an increasingly unmet need. Current perception suggests the use of anti-VEGF injections is likely to be beneficial in the management of new neovascularisation, leaving a gap in the treatment for established new vessels.

A number of techniques have been described in the literature for the treatment of CoNV. Ainslie et al (1962) suggested conjunctival resection for recalcitrant vessels, and in 1975 Reed et al published the use of argon laser to occlude neovascularisation on the cornea. Similarly, topical corticosteroids have been suggested, by Allredge et al in 1981, to promote regression. $^{7-9}$ This does, however, carry the side effects of increased intraocular pressure, reactivation of possible latent infection and cataract formation. In the current climate anti-VEGF agents have been shown to be effective in corneal new vessel regression, however no established treatment exists for 'established' corneal new vessels, which do not depend on VEGF drive to maintain patency. ${ }^{10} 11$

The principle of electrocautery to occlude vessels dates to the 1920s, but fine needle diathermy (FND) was initially coined as an office-based technique to occlude corneal neovascular vessels and published by Pillai, Dua and Hossain in $2000 .{ }^{8}$ Using a 10-0 monofilament nylon suture and a diathermy current, direct occlusion was achieved. In a follow-up of 14 patients over 10.3 months, $57.1 \%$ showed evidence of regression after one treatment. A case series of three patients published by Wertheim et al in $2007^{9}$ demonstrated an adequate safety profile, but the follow-up was 8 months and two patients required retreatment. Thus the issues of long-term safety and efficacy have not been evaluated for FND. The purpose of this study was to determine the safety, efficacy and medium-term to long-term outcomes of patients receiving FND for established CoNV.

\section{METHODS}

\section{The fine needle diathermy technique}

The decision to proceed with FND was taken on patients with established and stable CoNV, with diminished visual acuity and ocular surface symptoms. Informed consent was acquired. The periocular skin is sterilised using $5 \%$ povidone iodine for $3 \mathrm{~min}$. Fifty per cent diluted iodine is used for the ocular surface. Using an aseptic method a sterile drape is applied and a speculum is placed with care to move the eyelashes from the ocular surface. The procedure is usually performed under topical, subtenon or peribulbar anaesthesia. 
A 10-0 monofilament nylon suture is inserted to 50\% corneal thickness (approximately 500 microns depth at the limbus) immediately adjacent and at the proximal entry point of the corneal new vessel into the cornea. The vessel is placed tangentially, rather than parallel, to the corneal new vessel.

Monopolar electrocautery is performed using a nonalternating current from a diathermy machine. This is applied to the shaft of the nylon needle for 2-3 s. The circuit is composed of the generator, active electrode, patient (via an abdominal pad) and patient return electrode. Pathways to ground are numerous but may include the operating table, staff members and equipment. The patient's cornea provides the impedance, and heat is produced as the electrons overcome the impedance. The electrosurgical generator works at a frequency of over 200000 cycles per second, and coagulation setting 1 is used. A definite endpoint of localised vascular blanching is deemed appropriate treatment. This technique is then repeated as necessary for other new vessels in the cornea. Guttae chloramphenicol is applied as a stat dose, and the patient discharged with guttae chloramphenicol and Maxidex (dexamethasone 0.1\%) four times a day for 2 weeks, along with oral valaciclovir antiviral cover if there was a history of herpes simplex keratitis (HSK) (see online supplementary figure S1, clip 1).

A retrospective 5-year review of all patients undergoing FND at University Hospital Southampton (Southampton, UK) was performed, from October 2006 to October 2011.

Baseline demographics, including age, sex and previous treatments were documented. The site of surgery and the performing surgeon was retrieved, along with indication for treatment and ocular comorbidity(ies).

Preoperatively, the severity of CoNV was quantified by the number, depth and position of quadrant of vessels using subjective clinical examination and digital slit lamp photography as described by Bachmann et al (2008). ${ }^{4}$ In all cases CoNV were deemed quiescent. Intraoperative parameters (quadrant and number of vessels treated) were documented. Intraoperative complications, such as haemorrhage or corneoscleral perforation, were noted, along with the 'procedure time' taken for the procedure.

Preoperative and postoperative logMAR visual acuity was identified, as patients were treated (and retreated) primarily due to CoNV encroaching on the visual axis (secondary indications for treatment included prevention of progression, ocular discomfort and unacceptable cosmesis). Standards of logMAR 3.0, 2.7, 2.2 and 1.8 were used for no light perception, light perception, hand movement and count fingers vision, respectively. End points of treatment success were; the presence of ghost vessels, thinning, reduction, absence of vessels and qualitative resolution of lipid keratopathy, assessed by quantitative evaluation of the cornea and digital slit lamp photographs. Follow-up time, evidence of treatment regression and need for retreatment was recorded, with all statistical analysis performed using Qi Macros for Microsoft Excel 2012 (QiMacros, KnowWare International, Denver, USA). Retreatment was performed if the calibre of CoNV was unchanged, continued to interfere with the visual axis and no change in lipid keratopathy was observed after previous treatment.

This research adhered to the tenets of the declaration of Helsinki. Ethics approval was not required for this study. Audit approval was obtained from the University of Southampton Hospitals' National Health Service Trust Audit review board.

\section{RESULTS}

A total of 56 eyes from 52 patients underwent FND over the specified time period. The mean age of patients undergoing the procedure was 59.5 years (range 5-93 years, SD 18.7 years). In order to eliminate confounding variables, all patients receiving FND alone were included for analysis (47 eyes). This included 24 men and 23 women. Seven patients received corneal grafts prior to the FND procedure (six-penetrating keratoplasty, one -deep anterior lamellar keratoplasty). The most frequent indication was that of HSK (53\%) (table 1). The median number of quadrants of CoNV was two, and a mean of four vessels were treated per procedure. A clear correlation existed between the extent of CoNV and the preoperative visual acuity $(p=0.044$, Kruskal Wallis). The mean procedure time was $21.3 \mathrm{~min}$ (median $17 \mathrm{~min}$, range 8-54 min, SD $10.4 \mathrm{~min}$; figure 1b).

One complication was noted during the procedure-an intrastromal and subconjunctival haemorrhage (rate 2\%). This resolved with conservative treatment after 3 weeks. Small intrastromal haemorrhages were found to be common during the procedure, but were insignificant and inconsequential (figure 2). No systemic or other ocular adverse events were identified.

Our data showed that $68 \%$ patients showed regression after one treatment, and $89 \%$ of patients showed regression with two or fewer treatments (table 2). The average time between treatment and subsequent retreatment was 6.9 months (range 315 months). The mean number of treatments was 1.44 . Mean follow-up was 18.9 months (median 11 months, range 156 months, SD 13.4 months). No patient suffered a reactivation of CoNV following FND treatment, and no patient suffered corneal breakdown as a consequence of treatment. Five patients underwent corneal graft surgery after FND treatment (two of these had repeat corneal grafts and three corneal grafts for the first time).

\section{VISUAL ACUITY}

The mean visual acuity improved to $0.72 \log$ Mar, compared with a pretreatment mean average of $0.82(p=0.08$, Wilcoxon signed rank test). Insignificant correlation was found between the extent of CoNV treated (quadrants, number of vessels) and visual acuity outcome (Pearson's correlation coefficient -0.10 ).

The mean visual acuity was 1.68 after the first treatment compared with 1.51 post retreatment $(p=0.49$, Wilcoxon rank sum test).

\section{DISCUSSION}

This study has demonstrated, through the largest case series, with the longest follow-up, that FND is an effective treatment for established mature CoNV, with $68 \%$ showing regression after the first treatment. For those that required retreatment, the mean interval period was just under 7 months and principally due to CoNV encroaching on to the visual axis or ocular surface discomfort. Additionally FND demonstrates a satisfactory safety profile with minimal side effects, with only one intrastromal and

Table 1 Aetiology for fine needle diathermy

\begin{tabular}{lrl}
\hline Aetiology & $\mathbf{n}$ & Percentage (\%) \\
\hline HSK & 25 & 53.1 \\
Microbial/peripheral ulcerative keratitis & 6 & 12.8 \\
Exposure keratopathy & 4 & 8.5 \\
Cell deficiency & 4 & 8.5 \\
Corneal ulcer (non-infective) & 2 & 4.3 \\
Rosacea keratitis & 2 & 4.3 \\
Allergic eye disease & 4 & 8.5 \\
\hline HSK, herpes simplex keratitis. & &
\end{tabular}


(a)

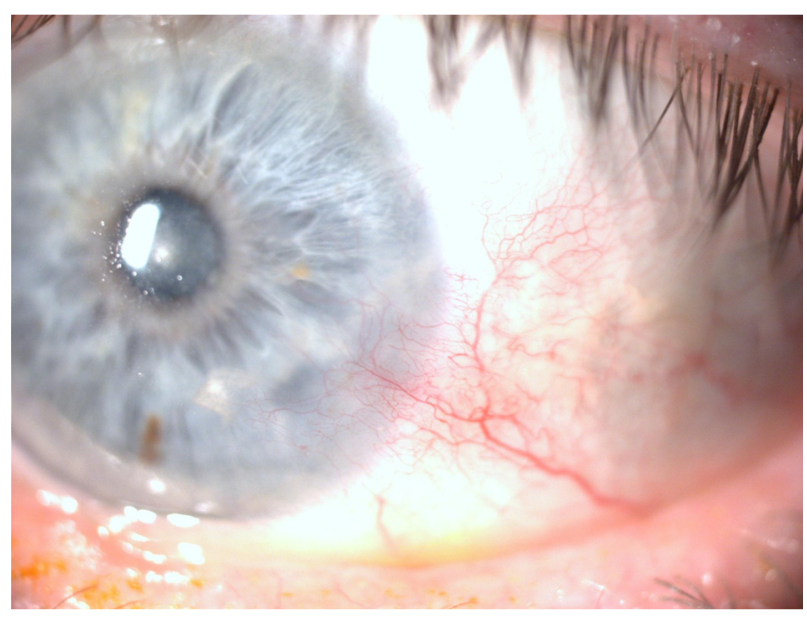

(b)

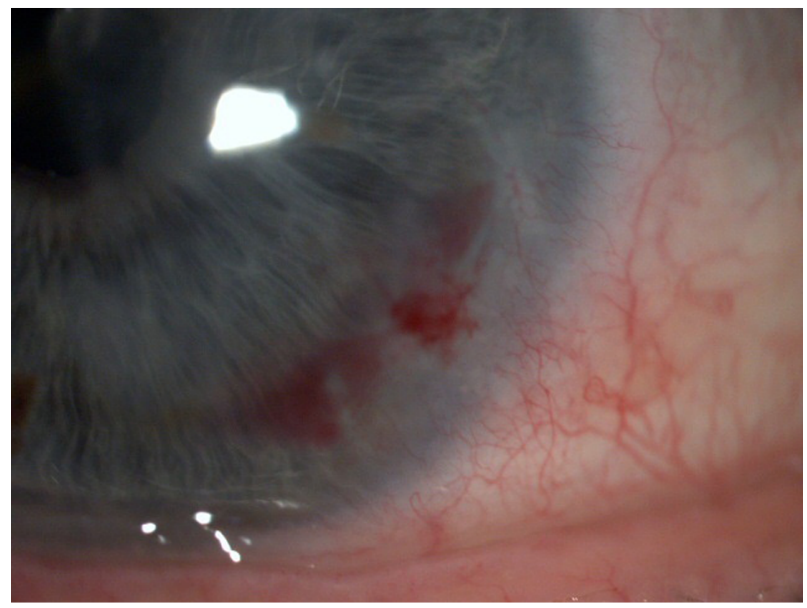

(c)

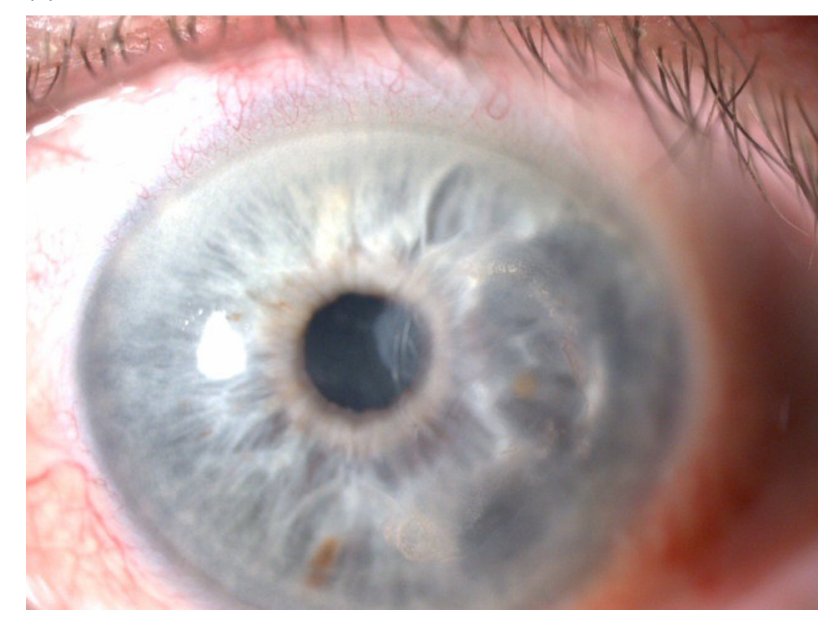

Figure 1 (A) Pretreatment. (B) Day 1 postoperatively. (C) 12 months post-treatment demonstrating marked regression of vessels and lipid keratopathy.

subconjunctival haemorrhage which resolved after 3 weeks. Overall, the procedure appears to be safe, rapid, cost effective (ie, requiring minimal equipment) and clinically effective. The most significant improvement in visual acuity was demonstrated in the HSK subgroup (table 3, figure 2) although a correlation existed between extent of CoNV and visual acuity preprocedure, the limitation in acuity improvement in all groups may vary due

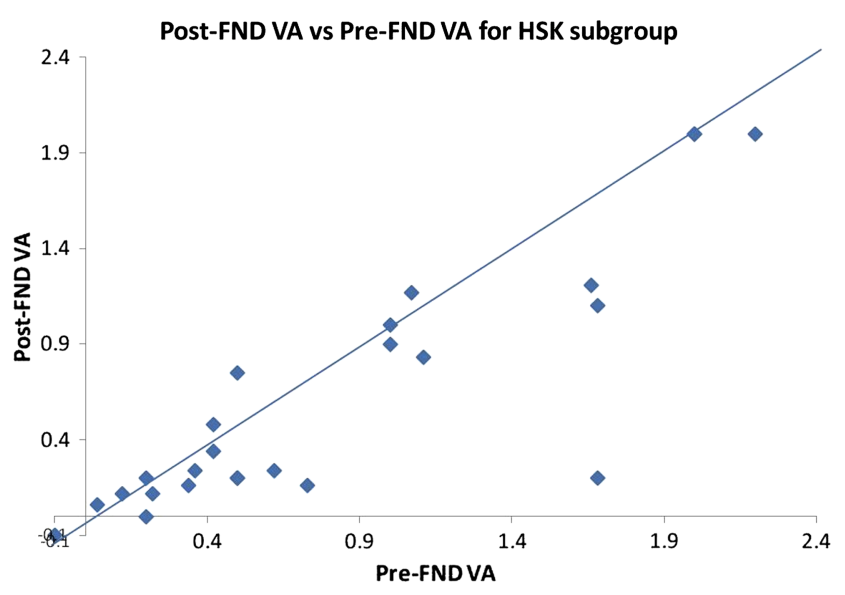

Figure 2 Scatterplot (logMar visual acuity (VA)) comparing Pre and Post fine needle diathermy visual acuity for the herpes simplex keratitis subgroup.

to the underlying pathological mechanisms, rather than CoNV resolution alone. Importantly, our mean follow-up was 18.9 months (range 1-56 months), and with the mean time for retreatment 6.9 months this therefore captures the patients requiring retreatment. No clinically observed cases of corneal ectasia were observed post treatment. The procedure is short and could be performed in an office based setting.

The data compares favourably with the original study by Pillai et al, who demonstrated a $57.1 \%$ success rate after one treatment. In this case series of 14 patients, 3 intrastromal haemorrhages and 1 crystalline deposit were detected. ${ }^{8}$ Similarly, Thatte et $a l^{12}$ highlighted a success rate of $100 \%$ after one treatment in 28 cases. The mean follow-up in this series was only 6 months in comparison with our study (18.9 months).

Limitations of our study include its retrospective nature, and an absence of a control group. Similarly, certain subgroups were small $(n=2)$. The analysis of the effect upon visual acuity could be improved through multivariate regression analysis as ocular comorbidity is a variable that may have been disproportionately less in the HSK subgroup compared with others. Our study could also have been improved by the assessment of corneal sensitivity, as a neurotrophic component may explain effect on efficacy of FND treatment. Acuity improvement in HSK could be hypothetically explained as while FND may reduce established CoNV, coexisting treatment with anti-inflammatories and antiviral agents may result in a decrease in neutrophil recruitment, interleukin (IL)-6 and IL17-A driven VEGF A production. ${ }^{13} 14$ Correspondingly, the absence of viral replication could enhance the production of sVEGFR-1, which binds to VEGF and prevents angiogenesis. $^{13} 15$

A high number of treatments were performed on patients with lipid keratopathy which contained established vessels and all cases the lipid keratopathy improved. An improvement in acuity in the HSK group may also have been due to unbalanced

Table 2 The effect of FND on corneal NV regression

\begin{tabular}{lr}
\hline FND Treatments to achieve regression & Number (\%) \\
\hline 1 & $27(57.4)$ \\
2 & $15(31.9)$ \\
3 & $5(10.6)$ \\
\hline FND, fine needle diathermy.
\end{tabular}


Table 3 Effect of FND upon visual acuity

\begin{tabular}{|c|c|c|c|c|}
\hline Aetiology & $\mathbf{n}$ & $\begin{array}{l}\text { Mean preop } \\
\text { VA (SD) }\end{array}$ & $\begin{array}{l}\text { Mean postop } \\
\text { VA (SD) }\end{array}$ & $\begin{array}{l}p \\
\text { Value }\end{array}$ \\
\hline HSK & 25 & $0.82(0.69)$ & $0.62(0.65)$ & 0.012 \\
\hline $\begin{array}{l}\text { Microbial/peripheral } \\
\text { Ulcerative keratitis }\end{array}$ & 6 & $1.06(0.91)$ & $0.90(0.73)$ & 0.249 \\
\hline Exposure keratopathy & 4 & $1.80(0.80)$ & $1.75(0.60)$ & 0.850 \\
\hline Cell deficiency & 4 & $1.25(1.01)$ & $1.11(1.03)$ & 0.361 \\
\hline Allergic eye disease & 4 & $1.84(1.11)$ & $1.71(1.14)$ & 0.201 \\
\hline $\begin{array}{l}\text { Corneal ulcer } \\
\text { (non-infective) }\end{array}$ & 2 & $1.85(1.20)$ & $2.45(0.35)$ & 0.371 \\
\hline Rosacea keratitis & 2 & $0.43(0.30)$ & $0.54(0.59)$ & 0.655 \\
\hline
\end{tabular}

reduction in lipid keratopathy and less corneal oedema in the optical zone. Our study was not powered to determine statistically significant differences in acuity, and therefore must be interpreted with caution. However, Bachmann et al's ${ }^{16}$ meta-analysis of anticorneal angiogenic therapies purported weak correlation between a reduction in CoNV and association with an improvement in visual acuity, and recommended further prospective randomised controlled trials, including morphological analysis of vascularisation forms and its effect upon acuity. ${ }^{16}$ It is likely that a larger trial would determine FND's efficacy in patients with HSK.

The extent of CoNV regression and need for retreatment may be affected by interobserver variability, as the power setting, time and manipulation of the diathermy electrode would be varied by the individual operating surgeon. The agreement of a definitive end point (that of localised blanching) does minimise this. Visual outcome is likely to have been affected by multiple ocular comorbidities, requiring multivariate analysis to determine the FND effect, although all patients requiring FND and other treatment interventions were excluded from our analysis. In addition, qualitative analysis of patient symptomatology revealed that most patients experienced less ocular surface discomfort post FND, and our study could be improved by the statistical analysis of a formalised Visual Function Questionnaire-25, correlated with preprocedure and postprocedure measurements of ocular surface tear film stability.

Research into the inhibition of CoNV continues apace, with anti-VEGF therapies (such as bevacizumab, ranibizumab and pegaptanib), VEGF-trap, siRNA and VEGF signalling tyrosine kinase inhibitors emerging as a leading treatment modality for 'new' CoNV. ${ }^{13}{ }^{14}{ }^{17}$ It is thought that inflammation induces VEGF-A production by a variety of cell types including macrophages and T cells. ${ }^{14} 18{ }^{19}$ A pilot study by Koenig et al, ${ }^{10}$ in which 16 eyes from 16 patients received diathermy vessel coagulation followed by treatment for up to 4 weeks with topical bevacizumab five times daily, demonstrated regression in 14 eyes. ${ }^{13}$ Patients were followed up for a mean of 276 days (range 29464 days). ${ }^{10} 16$ On balance, Stevenson's data suggest that ranibizumab's effects upon CoNV may be modestly superior when compared with bevacizumab's, with a statistically significant decrease in neovascular area noted in week 3 post treatment with ranibizumab (compared with week 6 with bevacizumab), although the authors recognised a pressing need for a head-to-head multicentre randomised controlled trial. ${ }^{20}$ Petsoglou $e t a l^{21}$ have demonstrated a statistically significant regression of corneal new vessels with three injections of bevacizumab compared with saline placebo. No adverse events were noted with either ranibizumab or bevacizumab use topically, although the most effective route of administration (topically, subconjunctivally or intracamerally) is yet to be elucidated. ${ }^{13}$ Rosenstein $e t ~ a l^{22}$ do, however, caution that the inhibition of ocular surface anti-VEGF may induce neurotrophic keratopathy inhibiting VEGF-mediated neural growth. ${ }^{13}$

The optimal assessment and treatment of CoNV is yet to be fully elucidated, with dose, duration and the timing of treatments not uniformly agreed upon. By using a standardised grading scale preoperatively and postoperatively, as has been suggested by Bock et $a l^{7}$ a more accurate treatment effect could be identified. Further refinement of imaging techniques that would allow assessment of vascular depth and quantification of vascular dynamics would be highly welcome. Indeed indocyanine green and fundus fluorescein angiography, along with in vivo confocal microscopy use, may serve as valuable tools in which to assess the extent of CoNV, and be useful to evaluate treatment. $^{23}$

Corneal disease is noted to be a leading cause of nonrefractive visual impairment worldwide, second only to cataract. ${ }^{19}{ }^{24} \mathrm{~A}$ gathering body of evidence suggests that antiangiogenic agents will play a pivotal role in the future, particularly for 'new' neovascularisation as this has been shown to be most responsive to VEGF blockade. ${ }^{4} 1016$ However, comparatively little is known about the nature of neovascularisation with different underlying aetiologies, and therefore neovascularisation responsiveness may differ across conditions. ${ }^{16}$ The actual effect of intervention may be calculated more accurately via the standardisation of neovascularisation quantification methods. ${ }^{16}$ Earlier intervention may help avoid the potentially serious complications of CoNV and for established deep and 'feeder' vessels, anti-VEGF may not be of benefit. ${ }^{13}$ While early work by Jo et al has demonstrated promising regression of established neovascularisation using coblockade of VEGF-A and platelet derived growth factor (PDGF) $\beta$, this has not been used in humans. ${ }^{13}$ We postulate that FND may be an officebased, inexpensive, useful, safe and effective treatment modality for established, mature corneal new vessels, as an adjunct to anti-VEGF use or for those recalcitrant to anti-VEGF blockade.

Acknowledgements Miss Becky Aston, Administrative assistant, University Hospital Southampton, Southampton, UK.

Contributors All authors cited in this manuscript have contributed equally to its production.

\section{Competing interests None.}

Patient consent Obtained.

Provenance and peer review Not commissioned; externally peer reviewed.

\section{REFERENCES}

1 Lee $\mathrm{P}$, Wang CC, Adamis AP, et al. Ocular neovascularization: an epidemiologic review. Surv Ophthalmol 1998;43:245-69.

2 Roberta P, Manzano A, Peyman G, et al. Inhibition of experimental corneal neovascularisation by bevacizumab (Avastin). Br J Ophthalmol 2007;91:804-7.

3 Cursiefen C, Colin J, Dana R, et al. Consensus statement on indications for anti-angiogenic therapy in the management of corneal diseases associated with neovascularisation: outcome of an expert roundtable. $\mathrm{Br} J$ Ophthalmol 2012;96:3-9.

4 Bachmann B, Taylor RS, Cursiefen C, et al. Corneal neovascularization as a risk factor for graft failure and rejection after keratoplasty: an evidence-based meta-analysis. Ophthalmology 2010;117:1300-5.

5 Azar DT. Corneal angiogenic privilege: angiogenic and antiangiogenic factors in corneal avascularity, vasculogenesis, and wound healing (an American Ophthalmological Society thesis). Trans Am Ophthalmol Soc 2006;104:264-302. 
6 Epstein RJ, Stulting RD, Hendricks RL, et al. Corneal neovascularization. Pathogenesis and inhibition. Cornea 1987;6:250-7.

7 Bock F, Onderka J, Hos D, et al. Improved semiautomatic method for morphometry of angiogenesis and lymphangiogenesis in corneal flatmounts. Exp Eye Res 2008:87:462-70.

8 Pllai CT, Dua HS, Hossain P. Fine needle diathermy occlusion of corneal vessels. IOVS 2000:41:2148-53.

9 Wertheim MS, Cook SD, Knox-Cartwright NE, et al. Electrolysis-needle cauterisation of new vessels in patients with lipid keratopathy. Cornea 2007;26:230-1.

10 Koenig Y, Bock F, Kruse FE, et al. Angioregressive pretreatment of mature corneal blood vessels before keratoplasty: fine needle coagulation combined with anti-VEGFs. Cornea 2012:31:887-92.

11 Anijeet ZR, Zheng $Y$, Tay $A$, et al. Imaging and evaluation of corneal neovascularisation using fluoroscein and indocyanine angiography. IOVS 2012;53:650-8.

12 Thatte $\mathrm{S}$. Fine needle diathermy — a choice for managing corneal neovascularisation. Nepal J Ophthalmology 2011;3:23-6.

13 Chang J-H, Garg N, Lunde E, et al. Corneal neovascularisation: an anti-VEGF therapy review. Survey Ophthalmology 2012;57:415-25.

14 Bock F, Maruyama K, Regenfuss B, et al. Novel anti(lymph) angiogenic treatment strategies for corneal and ocular surface diseases. Prog Ret Eye Res 2013;34:89-124

15 Gimenez F, Suryawanshi A, Rouse BT. Pathogenesis of Herpes Simplex Keratitis-A focus on corneal neovascularisation. Prog Ret Eye Res 2013;33:1-9.
16 Bachmann B, Taylor R, Curseifen C. The association between corneal neovascularisation and visual acuity: a systematic review. Acta Ophthalmologica 2013;91:12-19

17 Stevenson W, Cheng SF, Dastjerdi MH, et al. Corneal neovascularisation and the utility of topical anti VEGF inhibition: ranibizumab (Lucentis) vs. bevacizumab (Avastin). Ocular Surface 2012;10:67-83.

18 Avery RL, Pieramici DL, Rabena MD, et al. Intravitreal bevacizumab (Avastin) for neovascular age related macular degeneration. Ophthalmology 2006;113: $363-72$.

19 Whitcher JP, Srinivasan M, Upadhyay MP. Corneal blindness, a worldwide perspective. Bull World Health Organisation, 214-21. http://www.who.int/ncd/ vision2020_actionplan/documents/79(3)_214-21.pdf (accessed 21 Jul 2012).

20 Witmer AN, Vrensen GF, Van Noorden CJ, et al. Vascular endothelial growth factors and angiogenesis in eye disease. Prog Retina Eye Res 2003:22:1-29.

21 Petsoglou, Balaggan KS, Dart JK, et al. Subconjunctival bevacizumab induces regression of corneal neovascularisation-a pilot randomised placebo-controlled double masked trial. $\mathrm{Br}$ J Ophthalmol 2013;97:28-32.

22 Rosenstein JM, Krum JM. New roles for VEGF in nervous tissue—beyond blood vessels. Exp Neurol 2004;187:246-53.

23 Cursiefen C, Hofmann-Rummelt C, Küchle $M$, et al. Pericyte recruitment in human corneal angiogenesis: an ultrastructural study with clinicopathological correlation. $\mathrm{Br}$ J Opththalmol 2003;87:101-6.

24 Hosseini M, Nowroozadeh M, Salouti R, et al. Anti-VEGF therapy with Bevacizumab for anterior segment disease. Cornea 2012;31:322-24. 


\section{Long-term outcomes of Fine Needle Diathermy for established corneal neovascularisation}

S Trikha, S Parikh, C Osmond, et al.

Br J Ophthalmol published online January 23, 2014

doi: 10.1136/bjophthalmol-2013-303729

Updated information and services can be found at:

http://bjo.bmj.com/content/early/2014/01/23/bjophthalmol-2013-303729.full.html

These include:

Data Supplement "Supplementary Data"

http://bjo.bmj.com/content/suppl/2014/01/23/bjophthalmol-2013-303729.DC1.html

References This article cites 23 articles, 5 of which can be accessed free at: http://bjo.bmj.com/content/early/2014/01/23/bjophthalmol-2013-303729.full.html\#ref-list-1

$\mathbf{P}<\mathbf{P} \quad$ Published online January 23, 2014 in advance of the print journal.

Email alerting Receive free email alerts when new articles cite this article. Sign up in service the box at the top right corner of the online article.

Advance online articles have been peer reviewed, accepted for publication, edited and typeset, but have not not yet appeared in the paper journal. Advance online articles are citable and establish publication priority; they are indexed by PubMed from initial publication. Citations to Advance online articles must include the digital object identifier (DOIs) and date of initial publication.

To request permissions go to:

http://group.bmj.com/group/rights-licensing/permissions

To order reprints go to:

http://journals.bmj.com/cgi/reprintform

To subscribe to BMJ go to:

http://group.bmj.com/subscribe/ 


\section{Notes}

Advance online articles have been peer reviewed, accepted for publication, edited and typeset, but have not not yet appeared in the paper journal. Advance online articles are citable and establish publication priority; they are indexed by PubMed from initial publication. Citations to Advance online articles must include the digital object identifier (DOIs) and date of initial publication.

To request permissions go to:

http://group.bmj.com/group/rights-licensing/permissions

To order reprints go to:

http://journals.bmj.com/cgi/reprintform

To subscribe to BMJ go to:

http://group.bmj.com/subscribe/ 